\title{
THE SPECIFIC CHEMICAL THERAPY OF THE TRYPANOSOMIASES AND SPIRILLOSES *
}

\author{
B. T. TERRY, M.D. \\ NEW YORK \\ OUTLIXF: \\ TRYPANOSOMIASES
}

In general. Therapy since 1904. Four groups of medicaments.

Group 1. The benzidine dyes.

Group 2. The basic tryphenylmethane dyes.

Group 3. Arsenical compounds. (Sleeping sickness.)

Group 4. Antimony compounds.

Drawbacks and dangers of treatment. Resistant strains.

Variability of trypanosomes. Combined treatment.

\section{SPIRILLOSES}

1. Spirillosis of fowls. (South America.)

2. Spirillosis of African tick fever.

3. Spirillosis of European relapsing fever.

4. Syphilis.

\section{INTRODUCTION}

Concerning the specific chemical therapy of the trypanosomiases and spirilloses so much has been published in the last few years that it would be impossible in the time at my disposal to review even a large fraction of the work that deals with these two groups of diseases. Even if time permitted, to attempt such a thing would be out of place, for as important as these diseases are in tropical countries, the American phy. sician has only a general interest in most of them. Of necessity much will have to be omitted. In spite of this it seemed advisable to unite in one paper the therapy of these two groups of diseases, partly on account of certain analogies which exist between their etiological agents, but more particularly because some of the remedies found useful in the trypanosomiases have recently been applied successfully to the spirilloses. The trypanosomiases will be considered first.

\section{THE TRYPAXOSO.ILASES}

"Trypanosomiasis" is the general name given to a specific infection caused by microscopical protozoan organisms, trypanosoma. These dis-

"From Rockefeller Institute for Medical Research, New York.

* Read before the Section on Pharmacology and Therapeutics of the American Medical Association, at the Fifty-ninth Annual Session, Chicago, June, 1908. 
eases have a wide distribution and, according to Musgrave and Clegg', destroy millions of dollars worth of animals each year. Horses, asses, cattle and a number of different animals are subject to infection. As far as we know one species only, Trypanosoma gambiense, is pathogenic for man. As examples of these diseases we may mention nagana (T. brucei), or the "Tsetse fly disease" of Zululand, surra (T. evansi) of India, mal de caderas (T. equinum) of South America, dourine (T. equiperdum), formerly wide-spread in Europe, now confined almost exclusively to Algiers and to North America, and sleeping sickness (T. gambiense), the terrible human scourge in Africa.

Transmission.-In tropical countries these diseases occur in epidemic form: and the trypanosoma seem to be conveyed from animal to animal chiefly by the bites of flies and fleas. In the case of dourine in the horse, however, and probably also in certain cases of sleeping sickness $\left(K_{0} \mathrm{ch}^{2}\right)$, the transmission of the disease seems to be by coitus.

In general the diseases are characterized by an incubation period of variable length which is followed by fever and the appearance of trypanosoma in the circulating blood. "The mortality among most animals of economic importance is 100 per cent." (Musgrave and Clegg ${ }^{1}$ ).

Therapy Before 1904.- Prior to 1904 the most efficient medicament against the various trypanosomiases was arsenic, and this was insufficient. In the form of arsenious acid, sodium arsenite, or Fowler's solution, it prolonged the life of infected animals by driving the trypanosomes temporarily from the circulation, but by its use cures were almost never obtained. As a rule, relapse followed relapse and eventually one had to choose between letting the animal die of the trypanosomes or of the treatment.

Therapy Since 1904. - This was the discouraging situation when Ehrlich and Shiga began their search for medicaments active against the trypanosomiases. Their publication ${ }^{3}$ in 1904 marks the beginning of our recent progress and stimulated greatly the experimental study of the therapy of these diseases. Workers in various laboratories took up the problem and as a result we now possess a number of medicaments far more active than the older forms of arsenic. These newer medica-

1. Musgrave (W. E.) and Clegg (M. T.): Trypanosoma and trypanosomiasis, with special reference to Surra in the Philippine Islands. Gov. Biolog. Lab., Rep. 5, Manila, 1903. Bureau of Public Printing.

2. Koch (R.): Schlussbericht über die Tätigkeit der deutschen Expedition zur Erforschung der Schlafkrankheit. Deutsch. med. Wchnschr., 1907, xxxiii, 1889.

3. Ehrlich (P.) and Shiga (K.): Farbentherapeutische Versuche bei Trypanosomen-Erkrankung. Berl. klin. Wehnschr., 1904, xli, 329. 
ments may be conveniently divided into four groups (Table 1). 1. The benzidine dyes. 2. The triphenylmethane dyes. 3. Arsenic compounds and 4. Antimony compounds.

Table 1.-Newer Trypanocidal Medicamen'ts

GROUP I.-BENZIDINE DYES

1-T'Typan-red ("Trypanrot"). Ehrlich and Shiga.............. 1904

2-Dyes of Nicolle and Mesnil. (See Table 2) . . . . . . . . . . . 1906

GROUP II.-BASIC TRYPHENYLMETHANE DYES

1-Malachite Green and Brilliant Green. Wendelstadt and Felmer. 1904 and 1906

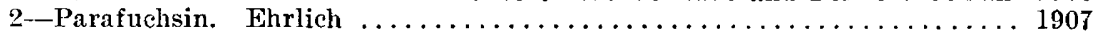

GROUP MII.-ARSENICAL COMPOUNDS

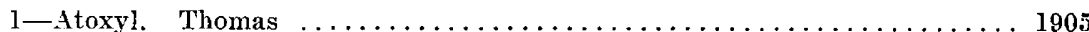

2-Acetyl-atoxyl and Paroxybenzyliden-atoxyl. Ehrlich........... 1907

GROUP IV.-ANTIMONY COMPOUNDS

1-Sodium Antimonyl Tartrate. Plimmer and Thomson. . . . . . . . 1905

¿-Potassium Antimonyl Tartrate. Mesnil and Brimont............ 1908

\section{TIIE BENZIDINE DYES}

In the study which led to the discovery of the first of the newer medicaments active against trypanosomes, Ehrlich and Shiga chose for their investigation the virus of mal de caderas and studied this in white mice. The latter were selected because they were so small and cheap that the experiments could be carried out on a scale large enough to exclude experimental error, and because in them the course of the infection was so regular that even a slight variation due to a medicament could be detected. For example, Ehrlich and Shiga found that mice inoculated with their strain of mal de caderas died with great regularity on the fourth or fifth day. A spontaneous cure or even a chronic course of the disease in untreated animals was never observed.

Trypan-red.-At first Ehrlich and Shiga had almost no guiding principle to direct them in their search. They had to try far more than a luundred substances before finding one or two that possessed even a slight activity against the trypanosomes. At last, however, they came upon a red dye belonging to the benzopurpurin series which possessed a certain activity. This activity was not great; it did not cure animals infected with the disease, but it lengthened life slightly. When this dye was disrovered the future problem was clearly outlined. It was necessary to increase its activity against the trypanosomes and to decrease its toxicity for the host. In this work Ehrlich found the chemist Weinberg of the greatest assistance. The latter made a careful study of the red substance, altered it chemically in many ways, and searched among the neighbors 
closely related to it for compounds still more active. As a result of long, careful, scientifically directed research, another red dye was found which was far more active against mal de caderas in mice than was the original one with which Ehrlich and Shiga started. In the great majority of the cases a single injection of this new dye in the therapeutic dose, made within forty-eight hours after the inoculation of the virus, was capable of driving the trypanosomes from the circulating blood and effecting a permanent cure. From its activity against trypanosomes and its red color this new substance was named trypan-red ("Trypanrot").

Trypan-red's Limited Efficiency.-The finding of trypan-red did not solve the problem of the therapy of the trypanosomiases, for it was soon discovered that the efficiency of this medicament was strictly limited. It could cure certain of the trypanosomiases, caderas (Ehrlich and Shiga ${ }^{3}$ ), mbori (Laveran ${ }^{4}$ ) and dourine (Halberstaedter") in mice, but against other infections in the same or in other hosts, the results, as a rule, were far from satisfying. For example, in the treatment of nagana in mice or rats a cure was almost never obtained, and the results were about as bad even in the treatment of caderas when the rat, instead of the mouse, was the host. From the limited efficiency of trypan-red it was evident that other and more powerful medicaments were needed and several workers, stimulated by the discovery of Ehrlich and Shiga, attempted to improve upon it.

Other Benzidine Dyes.-Nicolle and Mesnil ${ }^{6}$ at the Pasteur Institute, Paris, took up the problem. They conceived the idea of submitting to a systematic study the series of colors to which trypan-red belonged, hoping in this way to obtain medicaments more active than trypan-red and seeking to determine the conditions of activity of the active compounds. In both problems they were, to a certain extent, successful. They found a number of colors which were more active against some species of the trypanosomes than trypan-red, and determined a few of the conditions of activity,

Table 2.-Compiled from the work and tables of Nicolle and Mesnil, ${ }^{\circ}$ 'Table 2 shows the curative activity of the benzidine dyes against the try-

4. Laveran (A.): Le trypanroth dans le traitement de quelques trypanosomiases. Compt. rend. Acad. d. sc., Paris, 1904, exxxix, 19.

5. Halberstaedter (I.): Untersuchungen bei experimentellen Trypanosomen. Erkrankungen. Centralbl. f. Bakteriol. u. Parasitenk., Orig., 1905, xxxviii, j25.

6. Nicolle (M.) and Mesnil (F.): Traitement des trypanosomiases par les couleurs de benzidine, Première partie-êtude chimique. Ann de l'Inst. Pasteur, 1906, xx, 417; Seconde partic, etude expérimentale, Ann. de l'Inst. Pasteur, 1906, $\mathrm{xx}, 513$. 
panosomes of surra, caderas and nagana in mice. These animals were treated only after the typanosomes were visible in the blood and as a rule each animal received only one injection of the given medicament.

\section{TABLE 2.-BENZIDINLE DYES.*}

\begin{tabular}{|c|c|c|c|c|c|c|}
\hline \multirow[b]{2}{*}{ Chemical Composition. } & \multirow{2}{*}{ 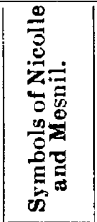 } & \multirow[b]{2}{*}{$\begin{array}{l}\text { Color of } \\
\text { Solution. }\end{array}$} & \multirow{2}{*}{ 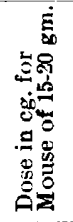 } & \multirow[b]{2}{*}{$\begin{array}{c}\text { Three species of } \\
\text { Trypanosomes } \\
\text { Treated. }\end{array}$} & \multicolumn{2}{|c|}{ Mice. } \\
\hline & & & & & 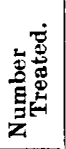 & 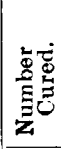 \\
\hline $\left.\begin{array}{c}\text { Amidonaphtol disulphonic } \\
\text { acid, 1. 8. 3. 6. }+ \text { dichlor- } \\
\text { benzidine. (Alk). } \dagger\end{array}\right\}$ & Cl. & Violet blue. & 1. & $\begin{array}{l}\text { Surra of India. } \\
\text { Mal de Caderas. } \\
\text { Nagana. }\end{array}$ & $\begin{array}{r}5 \\
4 \\
10\end{array}$ & $\begin{array}{l}4 \\
2 \\
3\end{array}$ \\
\hline $\left.\begin{array}{l}\text { Amidonaphtol disulphonic } \\
\text { acid, 1.8.3, 6. + tolidine. } \\
\text { (Alk.) } \text { (Trypanblau or } \\
\text { trypan-blue.) }\end{array}\right\}$ & $\mathbf{A}$ & Blue. . . & 1. & $\begin{array}{l}\text { Surra of India. } \dot{\ddagger} \\
\text { Mal de Caderas. } \\
\text { Nagana. }\end{array}$ & $\begin{array}{l}15 \\
26\end{array}$ & $\begin{array}{l}1 \\
5\end{array}$ \\
\hline $\left.\begin{array}{l}\text { Amidonaphtol disulphonic } \\
\text { acid, 1.8. 3. } 6 . \times \text { tolidine. } \\
\text { (Alk.) } \dagger \text { (Trypanblau or } \\
\text { trypan-blue.) }\end{array}\right\}$ & $i$ & Blue. & 1. & $\begin{array}{l}\text { Surra of India. } \\
\text { Mal de Caderas. } \\
\text { Nagana. }\end{array}$ & $\begin{array}{l}6 \\
9\end{array}$ & $\begin{array}{l}1 \\
3\end{array}$ \\
\hline $\begin{array}{l}\text { Naphtylamine disulphonic } \\
\text { acid, 2. 7.3.6. }+ \text { benzi- } \\
\text { dine. }\end{array}$ & Alpha & $\begin{array}{l}\text { Deep cherry } \\
\text { red. }\end{array}$ & .75 & $\begin{array}{l}\text { Surra of India.\$ } \\
\text { Mal de Caderas. } \\
\text { Nagana. }\end{array}$ & $\begin{array}{r}5 \\
13\end{array}$ & $\begin{array}{l}1 \\
3\end{array}$ \\
\hline $\left.\begin{array}{l}\text { B. Naphtylamine disul- } \\
\text { phonic acid,2.3.6. + ben- } \\
\text { zidine orthomonosul- } \\
\text { phonic acid (Trypanrot } \\
\text { or trypan-red.) }\end{array}\right\}$ & $\mathbf{T}$ & Cherry red. & $.50<$ & $\begin{array}{l}\text { Surra of India. } \\
\text { Malde Caderas. } \\
\text { Nagana. }\end{array}$ & $\begin{array}{r}7 \\
14 \\
13\end{array}$ & $\begin{array}{l}3 \\
6 \\
1\end{array}$ \\
\hline $\left.\begin{array}{l}\text { Amidonaphtol disulphonic } \\
\text { acid, 1. 8. 3. } 6 .+ \text { para- } \\
\text { diamidodiphenylurea. } \\
\text { (Alk.) } \dagger\end{array}\right\}$ & Ph. & Violet. & 1. & $\begin{array}{l}\text { Surra of India.\$ } \\
\text { Mal de Caderas. } \\
\text { Nagana. }\end{array}$ & $\begin{array}{r}4 \\
15\end{array}$ & $\begin{array}{l}0 \\
1\end{array}$ \\
\hline
\end{tabular}

*For details and for the chemistry of these compounds the work of Nicolle and Mesnil ${ }^{6}$ should be consulted. A shorter account of the chemistry of these dyes is given in English by Wenyon ${ }^{7}$ and another by Nabarro. ${ }^{\mathrm{s}}$

7. Wenyon (C. M.): Action of the colors of benzidine on mice infected with Trypanosoma dimorphon. Jour. Hygiene, Cambridge, 1907, vii, 273.

8. Nabarro (D.): Trypanosomes and trypanosomiases. Trans. from the French of Laveran (A.) and Mesnil (F.). Chicago, 1907, W. T. Keener \& Co.

$\dagger$ (Alk) indicates that the union of both side-chains to the base was effected in an alkaline medium.

\$ Action of the medican ent "doubtful."

$\S$ Action of the medicament "insufficient." 


\section{BASIC TRIPHENYLALTHANE DYES}

Malachite Green and Brilliant Green.-Following the discovery of trypan-red by Ehrlich and Shiga, Wendelstadt and Fellmer published their investigations. 'These had resulted in finding that malachite green $^{0}$ and brilliant green, ${ }^{10}$ basic dyes of the triphenylmethane series, were active against trypanosomes. Even when given in very small quantities these new dyes caused the trypanosomes of nagana to disappear from the blood of rats. Unfortunately the results were not permanent. In one case life was prolonged to the seventy-second day, but by the use of these dyes alone no cures were effected.

Besides being insufficient to effect cures, the dyes of Wendelstadt and Fellmer were capable of setting up violent inflammatory processes when introduced into the tissues. For this reason in their experiments these authors usually injected malachite green into the tails of rats, believing that these animals could bear the loss of large portions of the tail easier than they could extensive areas of skin.

Parafuchsin.-Many attempts to find more active medicaments belonging to the triphenylmethane series have been made. After extensive experimentation Ehrlich ${ }^{11}$ has concluded that parafuchsin is probably the most active known representative of this series. By repeating sercral times the subcutaneous injection of this medicament Ehrlich has effected a certain number of cures in mice infected with nagana. Unfortunately, cven with parafuchsin, repeated injections are apt to lead to necrosis or sloughing of the skin.

Parafuchsin Feeding.-To avoid these unpleasant sequelæ, Ehrlich attempted to introduce the drug in a different way, namely, by mouth. 'I'o do this certain technical difficulties had to be overcome, for when cakes that had been soaked in parafuchsin were offered to mice Ehrlich found that the taste of this medicament was so disagreeable to thes: animals that they! would starve to death before they would eat them. To obviate this difficulty before incorporating it into cakes Ehrlich heated the parafuchsin with an excess of oleic acid, converting it into a compound that was readily absorbable from the intestine, yet one that

9. Wendelstadt (H.): Ueber die Wirkung ron Malachitgrün und andereri verschiedenartigen Stoffen gegen Nagana-Trypanosomen bei weissen Ratten. b)eutsch. med. Wchnschr., 1904, xxx, ]711.

10. Wendelstadt (H.) and Fellmer (T.): Ueber Einwirkung von Brilliantgrün auf Nagana-Trypanosomen. Ztschr. f. Hyg. u. Infectionskrankh., 1905, lii, 263.

11. Ehrlich (P.): Chemotherapeutische Trypanosomen-Studien. Berl. klin. Wchnschr., 1907, xliv, 233, 280, 310, 34]. 
was no longer distasteful to his animals. After quickly becoming accustomed to the new parafuchsin oleate cakes, mice readily accepted them and lived on these alone for months at a time.

Prophylactic Action.-Ehrlich found that parafuchsin given in this form had a very strong prophylactic action. For example, mice almost never became infected with nagana if they were fed on parafuchsin cakes for some days both previous and subsequent to the inoculation of the virus. Furthermore, they rarely became infected if the feeding was commenced simultaneously with the introduction of the virus.

Curative Action.-The curative action of the parafuchsin was not pronounced. If the feeding of mice infected with nagana was begun as late as twenty-four hours after the introduction of the virus the cures effected were rare exceptions.

\section{THE NEWER COMPOUNDS OF ARSENIC}

The third group is that of the arsenical compounds. As we have already stated, the older forms of this medicament were insufficient. It is not to these but to the newer forms, atoxyl and its derivatives, that I wish to direct attention.

Atoxyl.-Atoxyl is the sodium salt of paramidophenyl arsenic acid and contains 24.1 per cent. of arsenic ${ }^{11}$. It had been used for about three years in the treatment of skin diseases and anemias before its action on diseases caused by the trypanosomes was known. Its introduction into the therapy of the trypanosomiases by Thomas ${ }^{12}$ in 1905 marlis a great advance in our attempts to cure these diseases.

The Advantage of Atoxyl.--Compared with the older arsenical preparations atoxyl possesses several distinct advantages. One of these is its slight toxicity. According to Blumenthal ${ }^{13}$ atoxyl is $1 / 40$ as toxic as Fowler's solution. Another advantage is that injections of the newer compound are less painful and irritating: and are said not to lead to sloughing of the skin. Most important of all, however, is the fact that the improvement which is noted after the use of the drug is far more apt to be permanent. In the treatment by atoxyl of various animals infected with the organisms of nagana, surra, mal de caderas, dourine

12. Thomas (H. W.): Some experiments in the treatment of trypanosomiasis. Brit. Med. Jour., 1905, i, 1140.

13. Blumenthal (F.): Ueber Metarsensïureanilid (Atoxyl) Med. Woche, 1902, iii, 163 . 
and sleeping sickness, Thomas, ${ }^{12,}{ }^{14}$ Uhlenhuth, ${ }^{15}$ Nicolle and Mesnil,॰ Yakimoff, ${ }^{16}$ Ehrlich, ${ }^{11}$ Browning, ${ }^{17}$ and others seem to have effected a certain number of definite cures.

Rapid Action of Atoxyl. - When injected in the proper therapeutic dose into animals infected with trypanosomes the action of atoxyl is usually rapid. In a number of cases Thomas ${ }^{12}$ found involution forms in the blood of the infected animals four to six hours after the administration of the drug, and by the eighteenth hour all the organisms had disappeared. While this may be regarded as the common course of events, exceptionally the injection of this medicament is less effective. Out of 105 mice infected with the organisms of nagana and receiving only a single injection of atoxyl, Browning states that from the blood of twenty-four of these the trypanosomes never disap. peared and the animals died of the disease.

Prolonged Treatment With Atoxyl.-In the treatment of the various trypanosomiases by atoxyl the best results have been obtained by giving the drug repeatedly over a long interval of time. Thomas and Breinl, ${ }^{14}$ who have tested the drug on a large number of animals infected with various trypanosomes, state that it is necessary to continue the administration of the medicament after all the favorable signs are present. As a rule they gave one or more injections each week for one to three months. In spite of this seemingly thorough treatment, from a report by Breinl and Todd, ${ }^{18}$ it would seem that a certain number of the animals which Thomas and Breinl regarded as cured afterward had relapses and died of the disease. The experience of those who have tested the drug most thoroughly indicates that a single injection of atoxyl is rarely sufficient and that even when numerous injections are made over a long period of time in many cases cures are not effected.

14. Thomas (H. W.) and Breinl (A.): Report on trypanosomes, trypanosomiasis and sleeping sickness, being an experimental investigation into their path. ology and treatment by $\mathrm{H}$. W. Thomas, and a description of the tissue changes by A. Breinl. Mem. 16, Liverpool Sch. Trop. Med., Liverpool, 1905, Williams and Norgate.

15. Uhlenhuth, Gross and Bickel: Untersuchungen uber die Wirkung des Atoxyls auf Trypanosomen und Spirochäten. Deutsch, med. Wehnschr., 1907, xxxiii, 129.

16. Yakimoff (W. I.) : Zur Behandlung der Dourine. Therapeutische Versuche mit Trypanrot an Laboratoriumstieren. Centralbl. f. Bakteriol. u. Parsitenk., Orig., 1907, xlv, 437.

17. Browning (C. H.): Experimental chemotherapy in trypanosome infections. Brit. Med. Jour., 1907, ii, 140.7.

18. Breinl (A.) and Todd (.J. C. ) : Atoxyl in the treatment of trypanosomiasis. Brit. Med. Jour., 1907, i, 132. 
Atoxyl and Sleeping Sickness.-Although atoxyl has been shown to possess a certain value in the treatment of experimental trypanosomiasis, its claim to our attention is derived less from this than from its importance in the treatment of human trypanosomiasis, or sleeping sickness. As a remedy against this infection practically all observers are agreed that atoxyl is the best medicament yet tried.

The Administration of Atoxyl.-Concerning the proper dose and the proper method of administering atoxyl there has been a great diversity of opinion. A discussion of these differences can not be entered into here. It seems more profitable to give instead the conclusions of Robert Koch, ${ }^{2}$ whose experience with this medicament in the treatment of sleeping sickness is far greater than that of all the other investigators combined.

The Duse.-According to Koch the proper dose of atoxyl in the treatment of human beings is $0.5 \mathrm{gm}$. In the case of sleeping sickness to use less is to delay the cure and to invite failure. To use more is dangerous, as Koch discovered when at one time he injected doses varying between 0.5 and $1 \mathrm{gm}$., hoping by this means to hasten the cures. In some of the patients that received these larger doses Koch soon observed a symptom he had never seen in untreated patients or in those that had received only $0.5 \mathrm{gm}$. 'This was a blinding, which in a comparatively short time developed in both eyes. In the beginning it was hoped that this symptom might be only temporary, but in Koch's patients, unfortunately, no improvement appeared and they remained permanently blind. As soon as Koch became convinced that the blinding was due to atoxyl the large doses were immediately reduced to $0.5 \mathrm{gm}$. and no other cases of blindness developed. In this connection it is interesting to note that the larger doses of atoxyl gave no better results than did the $0.5 \mathrm{gm}$, doses.

The Double Dose.-The $0.5 \mathrm{gm}$. of atoxyl is given by Koch on each of two succeding days. In his experience this method has been much more eflective than the injection of a single $0.5 \mathrm{gm}$. In one case in which only a single injection of this amount was given, the trypa. osomes reappeared in the blood after only five days. On the other hand, where the double injection was given the trypanosomes were much later in reappearing.

Double Injections licpcated.-With suitable intervals between, the double injections must be repeated many times to effect a cure. After cxtensive experimentation the method that Koch finally arlopted gave cxcellent results. It is as follows: Half a gram of atoxyl is injected subcutaneously or intramuscularly on each of two suceeding days, and. 
with intervals of ten days between, this double treatment is repeated for many months.

Internal Administration of Atoxyl. - With the internal administration of atoxyl Koch has had no success. The 0.5 gram dose given by mouth was found to be insufficient, as in about 30 per cent. of the cases the trypanosomes returned during the treatment. On the other hand, larger doses than this could not be used, as they called forth toxic symptoms just as similar doses had done when injected subcutaneously or intramuscularly.

Sleeping Sickness. - Before taking up the results obtained with atoxyl in the treatment of sleeping sickness a few words about the disease may not be out of place. Sleeping sickness is the name applied to the infection produced in human beings by Trypanosoma gambiense. The name, however, while aptly fitting the last stages of the infection is not at all descriptive of the earlier ones, in which the enlargement of. the cervical glands may be the only objective sign. Nevertheless an early diagnosis of the infection can easily be made by puncturing one of the enlarged glands and examining its contents microscopically. In this way the trypanosomes are so readily detected by skilled observers that Koch ${ }^{2}$ reports finding them in 347 out of 356 glands examined.

Kocli's Classification.-In order to make clear the action of atoxyl on his sleeping sickness patients, Koch found it desirable to divide those who came for treatment into two classes, the "slightly ill" and the "severely ill." In the slightly ill the only objective sign was the enlargement of the lymph glands, with the presence in these of trypanosomes. The patients felt unwell and complained of weakness, especially in the lower extremities. They often had pains in the head, breast or limbs. In these patients the duration of the disease varied from one month to a year or more. In the severely ill objective signs became prominent. The weakness that was previously subjective now often manifested itself in a trembling of the limbs, a dragging of the feet or a tottering gait. As this wealness became more and more marked the patients passed successively through the stages in which they walked alone with difficulty, then with a stick, and at last only when supported on both sides. Finally they could neither stand nor sit without being supported, consciousness was lost and death seemed close at hand.

The Slightly Ill.-The best results that Foch has had were obtained in the treatment of his first class, the slightly ill. Following the injections of atoxyl the trypanosomes disappeared promptly from the circulating blood and from the lymph glands, and the enlarged glands decreased in size until after sixty days, as a rule, they were no longer 
palpable. The symptoms of the disease were also favorably influenced, but the improvement here was slower in making its appearance. It was usually not noted until three or four weeks after the commencement of the treatment. The patients then began to feel better, their pains decreased and disappeared, their strength returned and they were again able to walk and work without inconvenience. In cases of this class Koch ${ }^{2}$ believes that a cure can be effected in four to six months.

The Severely Ill.-The results of the treatment of the severely ill have not been so good. This class was a large one and contained a number of patients that were desperately ill. When brought for treatment some were unconscious and apparently had only a short time to live. Under the influence of the atoxyl treatment, however, a number even of these have improved so much that they can again walk without assistance. Not a few have apparently been cured, their health remaining good during the ten months they have been under observation. Nevertheless the mortality has been high. Of the 374 patients 78 , or 22.9 per cent., are already dead. This 78 , however, includes a number that were so near death's door when they arrived that they lived to receive only 1 or 2 injections. If the patients that were insufficiently treated were excepted the death rate in this class would be only about half of what is here recorded. Comparing the mortality of the treated with that of untreated patients durizg a similar interval of time, Koch finds that the former is only a tenth or twentieth of the latter.

The Native.-The results obtained by Koch will be better appreciated if some of the characteristics of his patients, the African natives, are mentioned. Although in the beginning the negro is anxious to be treated, he makes a very bad patient. In order that the treatment may be successful it should be given for a long time, at frequent intervals. and in maximum doses. 'The negro, however, is not disposed to undergo a prolonged course of treatment. As soon as he feels a little better or becomes tired of the treatment he is apt to run away. Neither will he stand much pain. Since the internal administration of atoxyl has proved to be insufficient, this medicament is always given hypodermically. At times a single injection given in this way is sufficient to cause the negro to remain away for months before returning for a second injection. In the case of the colors, the injection of which is evidently quite painful, the dose can not be regulated by what is therapeutically necessary, but by the amount the patient will stand. So it comes about that in not one of the 1,633 patients that Koch has had has he been able to arminister the treatment exactly as he would have liked. 
With such patients to treat the results Foch has obtained are all the more remarkable.

Caution.-In spite of the favorable results of Koch, it is impossible at present to know whether or not any of his patients have been cured. It is true that no signs of a relapse have appeared in the patients he has treated for ten months, but this interval is entirely too short to enable us to conclude that the patients are cured. After two months of treatment some of the patients appeared cured, and the treatment was interrupted. The relapses that followed showed that a cure had not been effected.

Kopke's Unfavorable Results.-In this connection we should recall the results of Ayres Kopka, ${ }^{19}$ whose experience in the treatment by atoxyl of sleeping sickness is longer, if not so extensive as that of Koch's. In spite of the fact that Kopke has used large doses of atoxyl and has administered the drug for many months, his results have been distinctly unfavorable. Of his ten patients this investigator in 1906 reported having lost six.

In a later report ${ }^{20}$ Kopke gives the results of treating twenty-eight blacks and one white man. Of the twenty-nine only six were still living. For two of the latter the treatment had been stopped, in one case for a short while only, in the other for nine months. At the time of the report the last-mentioned patient was afflicted with partial blindness as a result of the treatment. Two of those that died had been treated for over a year, one for fifteen, the other for twenty-one months. In this time the first had received 39 , the second 54 grams of atoxyl. In spite of the large quantity of the medicament that had been administered, trypanosomes were found in the fluid withdrawn from these two patients at the last lumbar punctures made before their death.

Acetyl-Atoxyl and Paroxybenzyliden-Atoxyl.-Until recently atoxyl was our most efficient arsenical preparation. Thanks to Ehrlich, however, we now possess two other medicaments which, while containing about the same percentage of arsenic as atoxyl, are, for the mouse, only one-tenth as toxic. These preparations are acetyl-atoxyl and paroxybenzyliden-atoxyl, and in experiments on nagana in mice they have been found more than ten times as efficient as atoxyl. For example, Browning, ${ }^{17}$ in Ehrlich's laboratory, treated sixty-four mice with atoxyl. Of these, five, or a little less than 8 per cent., were cured. Under similar

19. Kopke (Ayres): Trypanosomiasis luumaine, xv Cong. internat. de mêd., l.isbon. Section xvii, 1906, 233.

20. Kopke (Ayres): La maladie du sommeil. Ber. ü. d. xiv Internat. Kong. f. Hyg. u. Demographie, Berlin, Sept. 23 to 29, 1907, iii, 720. 
conditions 33 nagana mice were treated with the newer preparations and 31 , or 93 per cent., were cured.

According to Browning ${ }^{17}$ these two newer preparations are the most efficient therapeutic agents known in the treatment of nagana infections in mice. If the treatment is instituted twenty-four hours after the infection begins, this investigator states that practically a certain cure can be effected with a single injection of these medicaments.

The Time of Intervention.- The results of treatment with these newer preparations indicates that the earlier the treatment is begun the better chance there is of effecting a cure. As has already been stated, Browning has found that he can effect a cure in practically all cases of nagana in mice by employing acetyl-atoxyl or paroxybenzyliden-atoxyl if the treatment is begun within twenty-four hours after the introduction of the virus. If, on the other hand, he waited until forty-eight hours after the infection commenced he found that a single injection of these medicaments no longer sufficed to effect a cure. Of eight mice treated in this way all died of the infection. In order to effect cures at this late stage of the infection-twelve to eighteen hours before the expected death of the mouse-Browning ${ }^{17}$ found it necessary to resort to repeated injections of the medicaments, and even then only about half of the animals were cured. Thus, in the treatment of 22 mice, by repeating the injections three to five times in each case, Browning cured 12, or 55 per cent., of them.

So strikingly good are the results obtained with acetyl-atoxyl and paroxybenzyliden-atoxyl in the treatment of mice that it seems incumbent on us to test these drugs wherever atoxyl has been found of value. In the beginning, however, one should proceed with great caution. It is not permissible to conclude that in other species of animals the results will be equally good, merely because favorable results have been obtained in the treatment of mice. In fact, Ehrlich ${ }^{11}$ has already determined that these medicaments vary greatly in their toxicity according to the species of animal treated. For the mouse, in which such brilliant results have been obtained, these newer preparations are peculiarly non-toxic. Un fortumately the same can not be said of their action on the horse and the guinea-pig.

\section{ANTIMONY COMPOUNDS}

A fourth group of medicaments active against the trypanosomes has recently been introduced. This is the group of the antimony compounds. The most active member of this group that Plimmer and Thomson ${ }^{21}$

2I. Plimmer (H. G.) and Thomson (J. D.): Further results of the experi. mental treatment of trypanosomiasis in rats; being a progress report of a committee of the Royal Society. Proc. Roy. Soc., Iondon, No. B, 536, 1908, lxxx, 1. 
have tested is sodium antimonyl tartrate. From their work on rats infected with the organisms of surra and nagana this medicament is regarded by these writers as superior to atoxyl. Its action on the trypanosomes is decidedly quicker. After its administration, at times within one-half hour, and usually within two hours, the trypanosomes disappear completely from the peripheral circulation, although they may have been numerous when the injection was made. Of thirtynine animals treated with solium antimonyl tartrate the majority were living fifty-two days later. Unfortunately this interval is too short for us to draw from it any definite conclusions.

Independent of Plimmer and Thomson and before the publication of their paper, other investigators turned their attention to the antimony compounds. Mesnil and Brimont, ${ }^{22}$ working with potassium antimonyl tartrate, found that the injection of the therapentic dose of this medicament usually caused the trypanosomes to disappear from the peripheral circulation of the infected animals in about two hours. In many cases, however, the disappearance was only temporary, the percentage of cures effected rarying with the organisms causing the infection. With mice infected with surra of India, surra of Mauritius and dourine these investigators have been able to effect cures in the majority of the cases after a single injection of the medicament. On the other hand, in the treatment of animals infected with the organisms of mal de caderas, Gambian horse sickness, sleeping sickness and two species of nagana, the results have been much less satisfactory.

\section{DHAWBACKS AND DANGERS}

In attempting to solve a problem as difficult as that of the therapy of the trypanosomiases, it seems almost inevitable that many substances should be tried which eventually will have to be abandoned. While the dyes, or colors, were the medicaments with which our first successes in the treatment of the trypanosomiases were attained, the drawbacks attending the use of most of these are so great that we are inclined to think they will play a minor rôle in the therapy of the future.

The Dyes.-In addition to imparting a bright, unnatural color (reit, blue or violet) to the skin and mucous membranes, the subcutaneous injection of the dyes seems to be quite painful and, in a certain number of cases, leads to induration or sloughing of the skin, to nephritis, or to

22. Mesnil (F.) and Brimont (E.): Sur l'action de l'émétique dans les trypan. osomiases, note préliminaire, l3ull. de la Soe. path. exotiq., 1908, j, 44 ; Sur la valeur curative de l'émétique dans les diverses trypanosomiases, ibid, 212. 
a chronic intoxication which may bring about the death of the animal long after the infection with the trypanosomes has apparently been cured.

Atoxyl.-As valuable as atoxyl has proved to be in the treatment of sleeping sickness, in the use of this medicament too much care can not be exercised. It has been clearly and repeatedly demonstrated that large doses of this drug may lead to permanent blindness. Twentytwo of Koch's 1,633 patients lost their sight and Kopke's experience has been relatively much worse. Of 29 patients treated 6 had ocular trouble and in 4 the blinding was complete. Fortunately for the future of the atoxyl therapy it seems that the blinding effect of this drug may be avoided by paying scrupulous attention to the dosage. In Koch's vast experience, loss of vision was observed only in those that received injections of more than 0.5 gram.

Acctyl-Atoxyl.-While in no way wishing to suggest that larger animals and man will behave under medication as mice and rats do, I should like to call attention to a phenomenon in these animals which is curious, persistent and little understood. Ehrlich ${ }^{11}$ was the first to notice that, when mice were treated with acetylatoxyl, not infrequently their characteristics became profoundly altered. Following therapeutic injections of this medicament in a certain number of cases these animals were converted into dancers or waltzers resembling strikingly the longknown Japanese waltzing mice. Round and round in their jars they would spin, first in one direction and then in the other. When once the dancing habit was acquired it usually persisted until the death of the animal. Often this did not occur until many months afterward.

\section{RESISTANT STRAINS}

One of the most interesting and important recent discoveries in connection with the trypanosomes is, that these organisms can acquire a marked resistance to medication. This resistance was first suspected by Ehrlich ${ }^{11}$ in mice infected with nagana and treated with parafuchsin cakes. Occasionally after the feeding was discontinued relapses occurred. In such cases, if the feeding was again resorted to, the trypanosomes disappeared from the circulation, but tended to reappear after the feeding was stopped. In some cases, with each successive relapse, the parasites yielded less and less readily to treatment, until a time finally came when the trypanosomes could no longer be driven from the circulation by the parafuchsin. Ehrlich concluded that one of two things had occurred. Either the organism of the mouse had acquired the power of 
rendering the parafuchsin harmless or the trypanosomes had become resistant to this medicament. A simple experiment shower that the latter hypothesis was the correct one. Into a normal mouse trypanosomes which no longer responded to treatment were inoculated and feecling with parafuchsin was instituted. It was found that this medicament was no longer able to drive the trypanosomes from the circulation. Mice infected with these organisms died in spite of treatment. The virus had acquired a new characteristic. A race of trypanosomes resistant to parafuchsin had been produced.

$A$ General Phenomenon.-That parafuchsin was not the only drug against which trypanosomes could be rendered resistant was soon evident. By means of the principle of insulficient treatment, races of trypanosomes have been produced which are resistant to several different medicaments. In the preparation of these feeding was usually resorted to, but in the case of medicaments not easily absorbed from the alimentary tract (trypan-red and trypan-blue, for example), these were injected in small quantities hypodermically, the doses being chosen so as to prolong life without rendering the blood free from the parasites. In this way races of trypanosomes have been produced which are resistant to one or more members of the four groups of medicaments now known to be active against trypanosomes. It seems possible to Ehrlich that we are here dealing with a general phenomenon, and that we will probably be able to obtain races resistant to other groups of trypanocidal chemicals, if, as is to be expected, these shall be found.

Persistence of Resistance.-When resistance to medication has once been acquired it tends to persist for an indefinite time. In Ehrlich's laboratory it has been found that a race of trypanosomes resistant to fuchsin retained its resistance to this medicament after passing throngh twenty-five normal mice. On testing the same strain after the fortieth passage, however, it was found to be no longer resistant. Similarly a strain of trypanosomes resistant to atoxyl at the end of six months wa: found to have lost its resistance after seven and three-fourths months (eighty-seventh passage). Some strains, on the other hand, have as yet shown no signs of losing their resistance.

Browning ${ }^{17}$ reports that a strain resistant to atoxyl retained its resistance after passing through 140 normal mice in the course of fourteen months.

Behavior Toward Other Medicaments. - A race of trypanosomes resistant to one medicament is usually resistant to certain other closely related medicaments. For example, trypanosomes that have become 
resistant to atoxyl acquire at the same time more or less resistance to acetyl-atoxyl and to paroxybenzyliden-atoxyl, and races resistant to trypan-red become in the same way resistant to trypan-blue. Nevertheless a race of trypanosomes resistant to one medicament or to a group of medicaments is not resistant to all. Toward medicaments of other groups (Table 1) it seems to acquire no resistance, being as susceptible to treatment with these as was the original species from which the race was developed. For example, trypan-red resistant races are not at all resistant to parafuchsin or to atoxyl, and atoxyl-resistant races show no resistance to trypan-red or to parafuchsin.

Iultiple Resistant Races-When a race of trypanosomes becomes resistant to a medicament, or to a group of these, its ability to acquire a resistance to other medicaments seems to be in no wise altered. Races of trypanosomes having a double and even a triple resistance have been produced. After having been first rendered resistant to atoxyl a strain of trypanosomes acquired a resistance to trypan-blue and then to parafuchsin. In this way a single strain of trypanosomes finally came to possess a strong resistance to all three of the groups of medicaments at that time known to be active against trypanosomes.

Natural Variability of Trypanosomes.-It is important to realize that the characteristics of trypanosomes are more or less variable and unstable. As we have already seen, under the influence of prolonged and insufficient treatment they easily acquire a resistance to the medicament used. This resistance may be completely lost in the course of a few months, or it may be preserved for a very long time, possibly for years. In addition to these acquired variations certain others have been roted in organisms that have never previously been subjected to treatment. If one attempts to treat a given species of the trypanosomes with a certain medicament, at one time the organisms may appear highly resistant, at another very susceptible. T'o distinguish these two phases Ehrlich ${ }^{11}$ proposes to call the race resistant to treatment tenax, that susreptible to treatment debilix. At times the simple passage of the trypanosomes through a rabbit suffices to convert a resistant (tenux) strain into a non-resistant (debilis) strain.

According to Ehrlich, the terms tenas and debilis have nothing to do with the virulence of the organisms. They refer merely to the resistance of the parasites towarl a speeific medicament. In one case an original nagana strain was separated into two strains, one of which was tenax, the other debilis to trypan-red. Nevertheless, for animals these two strains were found to be equally pathogenic. 


\section{COMBINED TREATMENT}

If the curing of cases that experience has shown are difficult of treatment be taken as the test of efficiency, probably the best results thus far obtained in the various cxperimental trypanosomiases have been secured by means of combined treatment. By combined treatment is meant the simultaneous or alternate use of two or more medicaments or methods of administration.

The value of thus associating two remedies in the treatment of experimental trypanosomiasis was early pointed out by Laveran. By injecting arsenious acid and following this up twenty-four hours later with trypan-red Laveran ${ }^{4}$ was able to effect definite cures where either of the medicaments used alone always failed.

Atoxyl and Mercury.-In the treatment of nagana in rats Moore, Nierenstein and Todd ${ }^{23}$ report having recently combined with marked success injections of atoxyl with those of the bichlorid of mercury. By giving atoxyl and then, after the trypanosomes had disappeared, injecting large doses of the bichlorid of mercury, these workers found that, of twenty-five rats thus treated, seventeen survived, apparently cured. The cause of death of four was unknown. Two were sacrificed and their organs were examined with negative results. Only two died of the trypanosomes. This result is all the more striking when we note that, of the fourteen rats used as controls and treated with atoxyl alone, not one was cured.

Acetyl-Atoxyl and Atoxyl-feeding.-One of the most striking examples of the value of combined treatment is furnished by Browning. ${ }^{17}$ Into each of eleven mice richly infected with nagana Browning injected $0.025 \mathrm{gm}$. of acetyl-atoxyl, and the next day began to feed these animals on biscuit containing atoxyl. The feeding was continued for ten or cleven days. Of the eleven animals thus treated, ten were permanently cured. With the same strain of trypanosomes and at a similar late stage in the infection, control experiments by the same author indicate that repeated injections of the acetyl-atoxyl would have saved only 55 per (ent. of these animals, while, if the medicament had been given only once, none of them would have been cured.

23. Moore (B.), Nierenstein (M.) and Todd (J. L.): On the treatment of trypanosomiasis by atoxyl (an organic arsenical compound), followed by a mercuric salt (mercuric chlorid), being a biochemical study of the reaction of a parasitic protozoon to different chemical reagents at different stages of its lifahistory. J3io-Chem, Jour., 1907, ii, 300. 


\section{THE SPIRILLOSES}

From the treatment of the trypanosomiases we now turn to that of the spirilloses. The term "spirillosis" is used in a general sense and means an infection caused by spiral organisms. The spirilioses, therefore, include infections with a variety of organisms, spirilla, spirochetes and treponemas. The only diseases that we shall take up here will be the South American spirillosis of fowls, African tick fever, European recurrent fever and syphilis. With the exception of the first, man is subject to all of these.

Treatment of the Spirilloses.-Uhlenhuth ${ }^{15}$ was the first to apply to one of the spirilloses treatment found effective among the trypanosomiases. In so doing he was influenced by the analogy which exists between trypanosomes and spiral organisms, and especially by the view of Schaudinn, that certain spirochetes represent special developmental stages of trypanosomes.

THE SPIRILLOSIS OF FOWLS

The spirillosis of fowls was the first of these diseases successfully treated. According to Uhlenhuth, ${ }^{15}$ this spirillosis begins with a high fever and diarrhea and often terminates in a fatal septicemia. The cause of the disease, Spirillum gallinarum, was discovered by Marchoux and Salimbeni in Rio de Janeiro in 1903. It is conveyed from chicken to chicken in nature by a small tick, Argas miniatus. In untreated experimental animals, the spirilla appear in the blood on the second day after inoculation, increase in number until the fourth to the sixth day, when they are present in very large numbers. On the seventh to the ninth day the crisis occurs, the organisms suddenly disappear from the circulation, and the animals that survive are immune. A natural immunity is seldom encountered. In inoculating forty fowls, Uhlenhuth found it only twice.

Atoxyl and the Spirilloses of Fowls.-The drug that Uhlenhuth ${ }^{15}$ found most efficient in the spirillosis of fowls was atoxyl. As a rule, it was injected intramuscularly, the usual dose for a chicken being 0.25 $\mathrm{gm}$. When used in this way the drug was found to exercise both a preventive and a curative action. If, for example, the atoxyl was injected into infected fowls before the appearance of the spirilla, these organisms were never found by examining fresh specimens of blood. If, on the other hand, the drug was used curatively, being injected much later, at a time when the spirilla were present in large numbers, these disappeared in twenty to thirty hours, while the blood of the controls 
still teemed with the organisms. The use of atoxyl, either preventively or curatively, was followed by a lasting immunity.

Slow Action of Atoxyl.-Although atoxyl may be used prophylactically and curatively, in neither case does the drug bring about an immediate and complete extermination of the parasites. For a few days following the injection of the medicament, the parasites are present in scanty numbers in the blood of the treated animals and may be detected by injecting the blood into susceptible animals or by carefully searching well-stained specimens of the blood. ${ }^{24}$ Even when atoxyl is mixed with the virus previous to the injection, the blood of animals receiving the mixture is infectious for other animals one, two and even three days after the injection. ${ }^{25}$

Determining the Therapeutic Dose.-In determining the maximum quantity of atoxyl that may be used in the treatment of animals infected with Spirillum gallinarum, it is not always safe to rely on results obtained by experimenting on normal animals. For example, Levaditi and MacIntosh ${ }^{2 \bar{s}}$ have found that the normal calfat, or Java sparrow (Padda oryzivora), can bear the subcutaneous injection of $5 \mathrm{mg}$. of atoxyl, while $2 \mathrm{mg}$. is all the infected bird can safely withstand.

Atoxyl in Vitro.-The action of atoxyl on $S p$. gallinarum has been studied in vitro. Levaditi and MacIntosh ${ }^{25}$ suspended the spirilla in a solution of atoxyl stronger than that necessary to cure the calfat and studied the effect at room temperature and at $38 \mathrm{C}$. No marked difference was observed between the spirilla in the atoxyl solution and those suspended in isotonic salt solution. At room temperature the parasites preserved their motility for several hours. Still more striking are the results of Uhlenhuth and Gross, ${ }^{24}$ who studied the effect of atoxyl on the parasites at a lower temperature. These investigators mixed 1 c.c. of blood rich in spirals with 1 c.c. of a 1 per cent. solution of atoxyl and placed the mixture in the ice-chest. In this mixture the virulence of the organisms was retained for six days and motile spirilla were observed as late as the eighth day.

Atoxyl in Vivo.-In an attempt to determine the action of atoxyl in vivo, Levaditi and MacIntosh injected subcutaneously and intraperitoneally into fowls and calfats a solution of atoxyl containing the spirilla in suspension and studied the effect of the medicament on these

24. Chlenhuth and Gross: Cntersuchungen iiber die Wirkung des Atoxyls auf die Spirillose der Hiihner. Arb. a. d. k. Gsndhtsamte., 1907, xxvii, 231.

25. Levaditi (C.) and McIntosh (J.): L'Influence de l'atoxyl sur la spirillose provoquée par le spirillum gallinarum. Compt. rend. Soc. de biol., 1907, Ixii, 1000 . 
organisms by withdrawing a little of the fluid from time to time and examining it. The results were similar in the fowls and in the calfats. For a time the spirilla retained their motility, but after several hours this was lost and they agglutinated. In the controls, which received the spirilla suspended in salt solution, the parasites never lost their motility.

No Fixation by Atoxyl.-That atoxyl is not fixed by $S p$. gallinarum has been shown by Levaditi and MacIntosh. Ten drops of blood rich in spirilla were mixed with fifty drops of a 2 per cent. solution of atoxyl. After two hour's' contact the spirilla were freed from the atoxyl by washing and centrifugation and then injected into normal calfats. These animals became infected, as did the controls.

The Influence of the IHost.-In the treatment by atoxyl of an infection with $S p$. gallinarum, the species of the animal infected may play an important part. Levaditi and MacIntosh have shown that when the mouse is inoculated intraperitoneally with these spirilla it takes the spirillosis in a fairly accentuated manner, but the infection is of short duration and not transmissible in series. Against this infection in the mouse atoxyl seems to be without effect. Even when the medicament is mixed with the virus before it is injected into the mouse, the infection is not prevented and runs a course that is indistinguishable from that in the controls.

How Atoxyl Acts.-From these experiments Levaditi and MacIntosh conclude that atoxyl acts only by the intermediation of the animal organism. They believe that this medicament modifies the host in such a way that the means normally employed to rid it of the spirilla are exaggerated. In this way the infection is rendered light, almost imperceptible, and the crisis is called forth earlier than the one that normally puts an end to the infection. The appearance of this critical process is determined by atoxyl, even in those animals, like the calfats, in which it scems never to occur in nature. Unless treated, these birds regularly die of the infection. 'That these animals have a veritable crisis following the injection of atoxyl is indicated by the fact that they become refractory and elaborate antibodies which may be detected by experiments in vitro, for example, the immobilizing action of the serum. ${ }^{25}$

AFRICAN TICK FEVIER.

African tick fever (Spirillum duttoni) is the next spirillosis to be considered. In the treatment of the experimental infection with the organisms of this disease, Vassal's ${ }^{26}$ best results have been obtained with the benzidine dyes, or colors. The red colors were superior to the blues, the most efficient medicaments being trypan-red and alpha (naphtyla- 
min disulphonic acid 2736 plus benzidin; see Table 2) of Nicolle and Mesnil.

Sp. Duttoni in Untreated Mice.--In Vassal's untreated mice the spirilla generally appeared in the blood of the animals in less than twenty-four hours after an intraperitoneal inoculation of the virus. The organisms increased rapidly during the next two or three days until they became more numerous than the red blood corpuscles. They then began to decrease and on the sixth to the seventh day suddenly disappeared. The first relapse occurred, as a rule, a day or two later, the spirilla reappearing in the blood to remain one, two or three days.

Trypan-Red and Alpha.-According to Vassal, ${ }^{26}$ both trypan-red and "alpha" exert a protective and a curative action on this spirillosis in mice. If either is injected subcutaneously in the therapeutic dose, simultaneously with the intraperitoneal injection of the virus, the appearance of the spirilla in the blood is sometimes completely prevented, sometimes delayed until the time of the first relapse. If, on the other hand, the colors are administered twenty-four to forty-eight hours after the inoculation of the virus, at a time, therefore, when the spirilla are more or less numerous in the blood, the organisms disappear within twenty-four hours, while in the controls they are still swarming.

Malachite Green.- In the treatment of mice infected with the spirilla of African tick fever, Vassal ${ }^{26}$ found that malachite green did not have an appreciable influence.

A toxyl.-However useful atoxyl may be in the treatment of certain spirilloses, animal experiments indicate that it has little or no activity against the organisms of African tick fever. In 1906, according to Vassal, ${ }^{26}$ Levaditi used atoxyl to free the tick-fever virus of a trypanosome that accompanied it, and somewhat later the former investigator, ${ }^{20}$ working with the same virus, found that atoxyl was without influence on the course of the infection in mice.

Atoxyl in the Treatment of Man.-In the treatment by atoxyl of tick fever in man, a similar failure is reported by Breinl and Kinghorn. ${ }^{97}$ Two cases of this disease were studied at the Liverpool School of Tropical Medicine. From the very first day both patients were given injections of a 20 per cent. solution of atoxyl. 'The injections were made daily for two weeks, beginning with 0.6 c.c. and increasing to 1 c.c. In spite of this, no influence was observed either on the parasites or on the course of the infection.

20. Vassal (.T. .J.): Action des couleurs de benzidine sur le spirille de la "tick ferer" (Sp. drtroni). Compt. rend. Soc. de biol., 1907, lxii, 414.

27. BreinI. (A.) and Kinghorn (A.): Ueber die Wirkung des Atoxyl bei afrikanischem Rïckfallfieber. Jeutsch. med. Wchnschr., 1907, xxxiii, 299. 


\section{EUROPEAN RELAPSING FEVHK}

The third spirillosis that we are to take up is European relapsing fever, the etiological agent of which is the long known Spirillum obermeieri. According to the work of Glaubermann, ${ }^{28}$ atoxyl, when administered in large doses, seems to have a favorable effect on this infection. In the course of a violent epidemic of the fever that raged in Moscow in the spring of $190 \%$, this investigator treated seventy patients. In each instance the true nature of the disease was determined by the finding of the organisms in the blood, and in the undoubted cases only those patients were chosen for treatment who were shown by their histories to be having the first attack. In order to have comparable results, in no case was the atoxyl treatment instituted until the day after the fall of temperature at the end of the first attack. The treatment was given daily. The first thirty patients received comparatively small doses; varying between 0.6 and $1.7 \mathrm{gm}$. in the course of six to eleven days. These patients were manifestly less well influenced than forty others that received 1.8 to $4.6 \mathrm{gm}$. of the medicament in seven to fourteen days. The maximum dose given was $0.5 \mathrm{gm}$. In the treated patients the interval between the first attack and the first relapse was apparently not altered by the atoxyl, but where a relapse occurred the duration of this was shortened by about forty hours, and in a number of cases the relapse seemed to have been prevented. For example, in untreated patients Glaubermann observed a first relapse in 87 per cent. of the cases, whereas in the forty patients last treated it occurred in 32 per cent.

\section{SYPHILIS}

Atoxyl and Syphilis.- Since the discovery that atoxyl is active against syphilis, a large literature ${ }^{29}$ has arisen on the use of this drug in the experimental and naturally acquired form of this disease. The results of animal experimentation will be given before the treatment of man is taken up.

Experimental Prophylaxis.-The prophylactic action of atoxyl in animals is easily shown. Rabbits ${ }^{30}$ inoculated with syphilitic virus and

28. Glaubermann (J.): Klinische Beobachtungen über die Einwirkung des Atoxyls auf den Verlauf des Rückfallfiebers. Berl. klin. Wchnschr., 1907, iii, 1143.

29. A review of the literature upon the use of atoxyl in syphilis may be found in Paul Salmon's article entitled: J.'Arsenic dans la syphilis. Am. de l'Inst. Pasteur, 1908, xxii, 66.

30. Uhlenhuth (P.), Hoffman (E.) and Weidanz (O.): Ueber die präventive Wirkung des Atoxyl bei experimenteller Affen- und Kaninchen-Syphilis. Deutsch. med. Wehnsehr., 190 $\bar{T}$, xxxiii, 1590. 
then treated regularly with atoxyl showed neither a specific iritis nor nodules on the iris, contrary to what occurred in the controls. Monkeys ${ }^{31}$ have also been protected by injections of this medicament. Of eight inoculated with syphilitic virus and treated at once with atoxyl, not one took the infection.

Abortive Action.-The power of atoxyl to abort syphilis is not limited to cases treated immediately after the infection. In one experiment of Metchnikoff's ${ }^{32}$ two monkeys were inoculated with syphilitic virus, and in neither case was treatment instituted until fifteen days later, when each received a single injection of atoxyl (33 $\mathrm{mg}$. pro kilo). No further treatment was given, yet neither of the monkeys contracted syphilis. The control showed the disease on the thirty-fourth day.

In searching for the interval during which atoxyl might act preventively, Metchnikoff, ${ }^{32}$ in one case, waited until the very beginning of the primary lesion before treating the monkey. Ten centigrams of atoxyl sufficed to stop at once the development of the lesion. In this case, however, the single injection did not abort the disease; the animal was not cured and a relapse soon occurred.

From this, according to Salmon, ${ }^{33}$ it would seem that, before the ap. pearance of the primary, atoxyl may be used prophylactically, but when this lesion is visible it is too late to abort the disease. According to this investigator, at the moment the initial lesion appears the infection scems to become definitely chronic and the necessary doses of atoxyl must be repeated for a long time to effect a cure.

Immunity.-No immunity against syphilis is acquired when the development of the disease has been prevented by atoxyl. For example, two monkeys, $3: 2$ previously protected from infection by atoxyl, were inoculated a second time with syphilitic virus, seventy-seven and ninetyone days, respectively, after the first inoculation. Both contracted characteristic primary lesions.

Experimental Cures.-In monkeys lower than the anthropoid ape, the initial lesion, attenuated syphilis, may be cured, according to Salmon, ${ }^{33}$ after a single injection of atoxyl. The lesion already appears modified after twenty-four hours, and at times in less than four days has almost completely disappeared.

31. Chlenhuth (P.) Hoffman (E.) and Roscher (K.): Untersuchungen über die Wirkung des Atoxyls auf die Syphilis. Deutsch. med. Wehnschr., 1907, xxxiii, 873 .

32. Metrolnikoff (E.): Sur la prophylaxie de la syphilis. Ann. de l’Inst. Pasteur, 1907 , xxi, 753 .

33. Salmon (P.): L'Arsenic dans la syphilis. Ann. de l'Inst. Pasteur, 1908, xxii, 66 . 
Relapses in Experimental Syphilis.-A single injection of atoxyl, however, is not always sufficient to cure even the lower monkeys. The primary lesion may disappear under the influence of the drug, but if the treatment is not repeated one may subsequently find at the site of the old lesion scales, or crusts, or an infiltration of the skin, testifying to a recrudescence in the activity of the parasites. ${ }^{33}$

Efficiency of Atoxyl.-As an indication of the efficiency of an energetic treatment by atoxyl we may refer to the fact that the inoculation of the organs (spleen and bone-marrow) of animals previously treated by atoxyl only rarely infects susceptible animals, ${ }^{34}$ while the inoculation of the organs of untreated animals nearly always does.

Prophylaxis in Man.-Metchnikoff ${ }^{32}$ reports the cases of two men who feared they had contracted syphilis and who begged to be inoculated prophylactically with atoxyl. Each of these received two injections of $0.5 \mathrm{gm}$. of atoxyl, and neither contracted the disease. Nevertheless, as it was impossible to be certain that the men treated had really been inoculated with syphilis, Metchnilioff declined to draw any conchusions from these cases.

Curative in Man.-Clinically the action of arsenic is comparable to that of mercury $\left(\mathrm{Salmon}^{33}\right)$. It cures the lesions that mercury cures $\left(\right.$ Salmon $\left.^{33}\right)$. It is the third specific $\left(\right.$ Hallopeau $\left.^{35}\right)$. Toward it all of the syphilides react in the same way $\left(\mathrm{Salmon}^{33}\right)$. The chancre heals rapidly $\left(\right.$ Salmon $\left.^{33}\right)$. Exanthemata disappear, papules flatten, annular syphilifes dry, ulcers heal, and gummata yield to its influence (Las$\left.\operatorname{sar}^{36}\right)$.

To eure the lesions of syphilis the drug must be properly given. If the dose is too small, it is without effect; if too large and given repeatedly, permanent blindness or intense intoxication, or both, may result. According to Salmon, the correct dose of atoxyl for man is $0.5 \mathrm{gm}$. He regards this dose as non-toxic, therapeutically necessary and sufficient, and states that it constitutes a maximum which it is useless and at times dangerous to surpass. ${ }^{33}$

This investigator uses weak solutions of the medicament, 10 to 15 per cent., and sterilizes these at $100 \mathrm{C}$. for two minutes. As aqueous solutions of atoxyl do not keep, it is best to prepare them only a short time before using. The injections may be made subcutaneonsly or intramuscularly.

34. Neisser (A.): Atoxyl bei Syphilis und Framboesie. Deutsch, med. Wchnschr., 1907, xxxiii, 1521 .

35. Hallopeau (H.) : Sur un danger de la médication par l'atoxyl et l'obligation qu'il impose. Bull. Acad. de med., 1907, lviii, 61.

36. Lassar (O.) : Atoxyl bei Syphilis. Berl. klin. Wehnschr., 1907, xliv, 684. 
Given in this way, atoxyl usually acts rapidly on the syphilitic lesions and seems to be without danger for the patients. In treating 181 patients, into whom Salmon ${ }^{33}$ made 1,349 injections of the drug, not one had ocular trouble. It is true that larger doses, up to $1 \mathrm{gm}$. and more, have been given without inconvenience, but the experience of Koch, who has tried the drug on a large scale in Africa in the treatment of sleeping sickness, teaches that $0.5 \mathrm{gm}$. is the safe dose.

Where Atoxyl Is Indicated.-The advocates of mercury and potassium iodid may question the need or value of atoxyl in the treatment of the average case of syphilis, but even they should admit that for some patients and for some lesions atoxyl is clearly indicated. Where patients manifest an idiosyncrasy toward mercury or potassium iodid and can not take these medicaments, atoxyl should certainly be tried. It should also be tested on those lesions and forms of syphilis which heal slowly or are refractory to mercury. It is perhaps in the treatment of such patients and lesions that the effect of the atoxyl treatment has been most brilliant.

Duration of Treatment.-How long the atoxyl injection will have to be continued before the disease can be considered cured can not yet be stated. The continued observation of many cases alone will decide this. From the well-known chronicity of the disease, however, it is evident that we must expect relapses if the treatment is stopped too soon. Even when the lesions appear healed and when large doses of atoxyl have been given, relapses are apt to occur if the treatment is interrupted. In one case a chancre that measured 3 c.c. was apparently healed after five injections of $0.75 \mathrm{gm}$. each. The treatment was stopped, and twenty dars later the chancre opened again $\left(\right.$ Salmon $\left.^{33}\right)$.

Idiosyncrasy.-Although atoxyl has shown its efficiency in many cases of syphilis, it can not be used in all. We must recognize that a certain proportion of people can not bear this drug well. The percentage of these among men is about 12 , among women it is still higher..$^{33}$ The symptoms of intoxication-colic, nausea, vomiting, etc.-appear about ten hours after the injection of the drug, sometimes after the first injection, but more frequently after the fourth. ${ }^{33}$ These symptoms rarely last longer than four hours, are more alarming than serious and are allayed by opium (Salmon ${ }^{29}$ ).

Limited Applicability of Atoxyl.-Atoxyl is not applicable in all cases. As we have seen, some patients can not take this drug. It is obvious that for these some other treatment must be employed. In addition to these cases, there are a few syphilitic lesions that are influenced slowly or not at all by atoxyl. For these we should use either a totally 
different treatment or else associate some other medicament with atoxyl, alternating or giving them simultaneously.

Alternative Treatment.-The injection of atoxyl may be alternated with that of mercury. From the work of Ehrlich on trypanosomes it would seem that by thus energetically attacking the organism of syphilis from two sides in quick succession the destruction of the parasites may be brought about more quickly and the production of strains resistant to either of the medicaments may be prevented. In practice Salmon ${ }^{33}$ has found that this method is very effective against lesions that have grown torpid or refractory when treated by either atoxyl or mercury alone.

Simultaneous Treatment with Two Medicaments. - The simultaneous administration of atoxyl and mercury is the last treatment of syphilis we will mention. Salmon ${ }^{33}$ reports having combined with his atoxyl injections the most varied mercurial treatments. It is gratifying to note that this double treatment with atoxyl and mercury has been given in the majority of the cases without inconvenience, but on the real value of this method the future alone will enable us to place a proper estimate. All that can be said at present is, that by this procedure already, according to Salmon, ${ }^{33}$ remarkable results have been obtained.

Rockefeller Institute. 